\title{
Environmental Determinants of Child Mortality in Nigeria
}

\author{
Mesike, Chukwunwike Godson \\ Department of Actuarial Science \& Insurance, University of Lagos
}

Nigeria

Mojekwu, Joseph Nnamdi (Corresponding author)

Department of Actuarial Science \& Insurance, University of Lagos

Nigeria

E-mail: jnmoje@yahoo.com

\author{
Received: October 24, $2011 \quad$ Accepted: November 15, $2011 \quad$ Published: January 1, 2012 \\ doi:10.5539/jsd.v5n1p65 \\ URL: http://dx.doi.org/10.5539/jsd.v5n1p65
}

\begin{abstract}
Globally, childhood mortality rates have decline over the years due majorly to various action plans and interventions targeted at various communicable diseases and other immunizable childhood infections which have been major causes of child mortality, but the situation seems to remain unchanged in sub-Saharan African countries, as approximately half of these deaths occur in sub-Saharan Africa despite the region having only one fifth of the world's children population. Many covariates associated with variations in infant and child mortality are interrelated, and it is important to attempt to isolate the effects of individual variables for proper and effective interventions. This study examined the environmental determinants of child mortality using principal component analysis as a data reduction technique with varimax rotation to assess the underlying structure for sixty-five measured variables, explaining the covariance relationships amongst the large correlated variables in a more parsimonious way and simultaneous multiple regression for child mortality modelling in Nigeria. For purpose of robustness, a model selection technique procedure was implemented. Estimation from the stepwise regression model shows that household environmental characteristics do have significant impact on mortality.
\end{abstract}

Keywords: Child mortality, Environmental determinants, Sub-Saharan Africa, Mortality rate, Varimax rotation, Principal component analysis

\section{Introduction}

Health and life actuaries have always had an especial interest in the development and construction of mortality rates as actuarial mortality reflect a country's socio-economic level of development and quality of life and are used for monitoring and evaluating population and healthcare intervention programs and policies. Child mortality reduction, the fourth of the United Nation's Millennium Development Goals (MDGs) to reduce by two thirds the mortality rate of children under five between 1990 and 2015 has become a common agenda of public health and international development agencies (Mutunga, 2007). According to Espo (2002), approximately 10 million children under-five years die each year with large variation across region and countries. Globally the number of deaths among children under age five has reduced from 12.4 million in 1990 to 8.1 million in 2009 (UNICEF, 2010) majorly due to interventions targeted at communicable diseases such as malaria, measles, diarrhoea, respiratory infections and other immunizable childhood infections which have been major causes of child mortality. However, these health gains were short lived especially in Africa because disease oriented vertical program alone were not effective (Mutunga, 2007). Environmental, maternal and socio-economic factors were acknowledged as additional important determinants of child survival (Espo, 2002).

Child mortality rates still remain unacceptably high in sub-Saharan African countries as approximately half of childhood deaths take place in sub-Saharan Africa despite the region having only one fifth of the world's children population (Smith, 2010). For instance, in sub-Saharan Africa, 1 child in 8 dies before age five- nearly 20 times the average of 1 in 167 in developed parts of the world (Ojikutu, 2008). Similarly, UNICEF (2010) in the state of the world's children report noted that 8.1 million children across the world who died in 2009 before their fifth birthday lived in developing countries and died from a disease or a combination of diseases that could easily have been prevented or treated. It also noted that, half of these deaths occurred in just five countries 
namely, India, Nigeria, the democratic republic of Congo, Pakistan and China with India and Nigeria both accounting for one third of the total number of under five deaths worldwide. The report describes the declining rate as disturbing and grossly insufficient to achieve the MDG goal by 2015 as only 9 out of the 64 countries with high child mortality rate are on track to meet the MDG goal.

Though, common causes of child mortality and morbidity include diarrhoea, malaria, measles and acute respiratory infections, studies have shown that in Nigeria, many children die mainly from malaria, diarrhoea, whooping cough, tuberculosis and bronchopneumonia (Ogunlesi, 1961; Baxter-Grillo \& Leshi, 1964; Morley, 1973; Animashaun, 1977; Ayeni, 1980). Ogunjuyigbe (2004) viewed morbidity and mortality of the child to be influenced by the underlying factors of both biological and socio-economic that operates through proximate determinants. Jinadu et al. (1991), in a study, found dirty feeding bottles and utensils, inadequate disposal of household refuse and poor storage of drinking water to be significantly related to the high incidence of diarrhoea. In spite of enormous literatures on child mortality, it has been particularly difficult to determine the virtual importance of various diseases and conditions as causes of children's death of different age group (Ewbank \& Gribble, 1993). In Africa, the data on causes of death are generally unreliable and incomplete as such events are often not wanted to be remembered let alone be documented; therefore researchers have often relied on the use of verbal autopsy in determining the probable cause of death (Garinne \& Fontaine, 1986; Gray et al., 1990; Adeyemi et al., 2008). The technique relies heavily on the available clinical, demographic as well as epidemiological evidences to determine the probable cause of death and hence there may be possibility of false attribution and eminently spurious correlation (Adeyemi et al., 2008).

Although, several studies by health actuaries exists on child mortality, evidence on why the rates is still high in Nigeria in spite of various action plans and interventions made remain sparse. Possibly, the cause of disease and death over which not much controversies and uncertainties exist is the total environment of man (Adeyemi et al., 2008). Malaria, acute respiratory infections, measles, and diarrhoea which are today major causes of mortality for children under five are consequence of the built environment of man. In developing countries like Nigeria, one in eight children does not live to see their fifth birthday due to avoidable environmental threats, resulting into approximately 11 million avoidable childhood deaths yearly (WRI, 1999; World Bank, 2004). According to World Bank (2001) in a recent study, environmental risk factors were estimated to account for about one-fifth of the total burden of disease in low income countries. The WHO (2002) similarly, reported in Mutunga (2007) that among the ten identified leading mortality risks in high mortality developing countries, unsafe water, sanitation and hygiene ranked second while smoke from solid fuels ranked fourth. About 3\% (1.7 million) of the resulting deaths are attributable to environmental risk factors and child deaths account for about $90 \%$ of the total. The environmental burden of disease as noted by Listorti and Douman (2001), in Adeyemi et al. (2008) was highest in Sub-Saharan Africa with $26.5 \%$ while the average for all less developed countries was $18 \%$.

Environmental health risks are broadly categorized into two (Shyamsundar, 2002). The first are the traditional hazard related to poverty and lack of development, such as waste disposal, vector borne diseases, inadequate sanitation, air pollution (indoor) and lack of safe water while the second emanated from the modern hazards such as rural air pollution and exposure to agro industrial chemical and wastes, caused by development that lacks environmental safeguards. Faced with this environmental health threats, and coupled with the world desired to reduce child mortality worldwide as reflected in the MDG goal, understanding the factors responsible for high incidence of mortality is expedient and prudent. This study therefore uses principal components analysis with varimax rotation as data reduction technique to assess the underlying structure for the sixty-five measured variables and a robust simultaneous regression for child mortality modelling in Nigeria.

The aim of this study is to explore the household's environmental and socio-economic characteristics and their effect on child mortality, particularly to assess the relationship between the environment and childhood mortality in Nigeria and identify the environmental determinants of child mortality, controlling for other covariates.

The rest of this paper is organized as follows. The next section reviews the relevant literature while the materials and methods are described and details specification of the data reduction technique discussed in the third section. Section four provides the results and discusses the resulting inferences while section five concludes.

\section{Literature Review}

Several actuaries have investigated the determinant of child mortality for effective healthcare intervention and programme evaluation of clinical and financial outcomes (Guyatt et al., 1999; Cousins et al., 2002; Zhao et al., 2003; Mesike et al., 2012). For other studies that focuses on the determinant of child mortality (Ojikutu, 2008; 2010; Wolpin, 1977; Caldwell, 1979; Ouma, 1991; Espo, 2002; Mutunga, 2007; Adeyemi et al., 2009; Rahman et al., 2009). Child mortality risks can be viewed from the framework of a health production function to depend 
on both observed health inputs and unobserved biological endowment or frailty (Mutunga, 2007). Excluding these unobserved characteristics or existing relation between children within a family may lead to inefficient estimators (Ridder \& Tunali, 1999). There are many different frameworks with which the effect of different determinants on childhood mortality may be considered. Demographic studies by Mosley and Chen (1984) and Schultz (1984) distinguished between socio-economic (exogenous) and biomedical (endogenous) factors. The effect of these exogenous variables are said to be indirect as they operate within the endogenous biomedical factors called proximate determinants (Mutunga, 2007). Mosley and Chen (1984) in their study categorized these proximate determinants into maternal, environmental, nutrient deficiency, injuries and personal illness control factors.

Several studies on infant and child mortality have been carried out using census and survey data. Most of these studies have estimated child mortality using indirect methods such as Trussel's technique and Preston method (Mojekwu \& Ajijola, 2011; Jada, 1992; Omariba, 1993; Okumbe, 1996; Wanjohi, 1996). In Nigeria, Oni (1988) uses indirect methods to estimate level of mortality in Ilorin. Ogunjuyigbe (2004) combine Samoza method and univariate and bivariate analysis to calculate mortality indices for each woman in Ondo and Ekiti state. Ozumba and Nwogu-Ikojo (2008) applied multiple regressions with autocorrelation adjustment to estimate mortality. Antai et al. (2010) employ the multilevel logistic regression while Doctor (2011) uses multivariate logistic regression. All these studies find demographic, socio-economic and environmental factors (source of drinking water, sanitation facilities) to be significantly related to infant and child mortality.

Espo (2002) in his study, use indirect methods to estimate levels and trends of mortality in Malawi. The results indicate that source of drinking water and sanitation facilities are strong predictors of child mortality. Also, Folasade (2000) in her study to determine the relative significance of environmental and maternal factors on childhood mortality in southwestern Nigeria find that child mortality rate continued to be a function of an environmental factor namely source of drinking water and a child care behaviour factor, where the child was kept when mother was at work. Similarly, Timaeus and Lush (1995), in a comparative study of rural areas of Ghana, Egypt, Thailand and Brazil, discover that children's health is affected by environmental conditions and the economic status of the household. Hala (2002) utilized duration modelling to assess the impacts of water and sanitation on child mortality in Egypt. Though sanitation is found to have more pronounced impact than water, the results also show that access to municipal water reduces the risk of mortality. A Bayesian geoadditive survival model was introduced by Adebayo et al. (2002) to analyze child mortality in Nigeria. The results show the existence of a district-specific geographical variation in the level of child mortality.

Klaauw and Wang (2003) developed a flexible parametric hazard rate framework for analyzing child mortality. Their model predicts significant correlation between child mortality and access to electricity, provision of sanitation facilities, improving maternal education and reducing indoor air pollution. Jacoby and Wang (2003) in a related study, examine the linkages between child mortality, morbidity, and household quality and community environment in rural China using a competing risks approach. Their findings among others show that the use of clean cooking fuels, access to safe water and sanitation reduces the risks of child mortality. In examining the environmental determinants of child mortality in Ethiopia, Wang (2003) constructed three hazard models (the Weibull, the piecewise Weibull and the Cox model) to study three age-specific mortality rates by location, female education attainment, religion affiliation, income quintile, and access to basic environmental services (water, sanitation and electricity). The results show a strong statistical relationship between child mortality and poor environmental conditions.

However, many covariates associated with variations in infant and child mortality are interrelated, and it is important to attempt to isolate the effects of individual variables for proper and effective interventions. This study uses principal component analysis (PCA) as a data reduction technique to represent and explain the covariance relationships amongst large scale correlated variables in a more parsimonious way.

\section{Materials and Methods}

\subsection{Data}

The study uses data from the Nigeria Demographic and Health Survey (NDHS) 2008 and the annual abstract statistics of the National Bureau of Statistics (NBS) 2009. The annual abstract of statistics, is the standard summary of data on society, economy and organizations in the Federal Republic of Nigeria. It is a convenient reference source for statistical and related information, with appropriate introductions to the various sections. The 2008 NDHS is the fourth comprehensive survey conducted in Nigeria as part of the Demographic and Health Surveys (DHS) programme. The NDHS provides information on levels and trends in fertility, nuptiality, early childhood mortality and maternal mortality, maternal and child health, health issues, socio-economic and 
environmental conditions. The 2008 NDHS is a nationally representative survey of 33,385 women aged 15 to 49 and 15,486 men aged 15 to 59 in a randomly selected households across the six geo-political zones in Nigeria. Childhood mortality estimates are based on information from women's birth histories collected from a special survey questionnaire for women called the women questionnaire. For each of these births, information was collected on sex, month and year of birth, survival status, and current age; and, if the child had died, the age at death is collected. The reliability of mortality estimates depends on the sampling variability of the estimates and on non-sampling errors. Non sampling errors depend on the completeness with which child death are recalled and reported, and the accuracy of the date of birth information for living children, and the age at death information for deceased children provided by the mother.

Typically, the most serious source of non-sampling errors in a survey like this that collects retrospective information on births and death is the underreporting of births and deaths for children who were not living at the time of the survey. Several DHS studies show evidence of downward bias in reporting child death (Jacoby \& Wang, 2003). For example, mothers may be reluctant to talk about their dead children either because it brings back sad memories or because their culture discourages mention of the dead. Even if a respondent is willing to talk about a dead child, she may forget events that happened in the more distant past, particularly if a child was alive only for a short time. However, statistical examination of the ratios shows no significant omission as it varied from below 1 percent and 3 percent in the 2008 NDHS.

\subsection{Measurement of Variables}

The households' type of cooking fuel is categorized into two parts. Household using electricity, liquefied petroleum gas and kerosene are classified users of low-polluting fuel while those using wood and coal are considered users of high-polluting fuel.

In this study, we categorized households into rich and poor by poverty headcount using self-rated lines computed by the NBS.

Households are classified as having an improved toilet (has sanitation) if the toilet is used only by members of one household and if the facility used by the household separates the waste from human contact. Similarly, households with access to piped source within the dwelling or plot, public tap, tube well or borehole, and protected well or spring are considered having safe water. Also, mothers who completed at least primary education are considered to be educated.

\subsection{Methods}

Principal components analysis is used to represent and explain the covariance relationships amongst the large scale correlated variables; sanitation, safe water, electricity, maternal education, employment status, infant immunization, average person per household, type of cooking fuel, housing unit type, type of flooring material, method of solid waste disposal, type of roofing material, type of refuse disposal facilities, economic status (rich) and monthly household income in a more parsimonious way. We then carried out a simultaneous regression model to describe the relationship between the dependent variable $\mathrm{Y}$, mortality rate, and explanatory variables $\mathrm{X}$, the identified components. For purpose of robustness, stepwise regression as a model selection technique procedure was carried out to ascertain the major determinant factors of child mortality. The model is checked to ensure that the underlying assumptions are fulfilled. The explanatory variables are classified into two groups: environmental and socio- economic. The choice of these variables was guided by the determinant of child mortality literature. However the main focus of this study is on the environmental variables.

\subsection{Principal Component Analysis (PCA)}

Principal components analysis helps to represent and explain the covariance relationships amongst $P$ metrical correlated variable in terms of a much smaller number of uncorrelated variables termed factors (Bartholomew et al., 2002), by taking linear combination of the standardized observables over the specified samples in a more parsimonious way (Leech et al., 2008). This is most useful if one wants to reduce a relatively large number of variables to a smaller number of variables that still capture the same information, as it is much easier to interpret two or three uncorrelated variables than twenty or thirty that have a complicated pattern of interrelationships.

\subsection{The Outline of PCA}

Principal components analysis transforms a set of correlated variables ( $x$ 's) into a set of uncorrelated components $\left(y^{\prime} s\right)$. The principal components are linear combinations of the $X^{\prime} s$ (Bartholomew et al., 2002) which is written as

$$
y_{1}=a_{11} x_{1}+a_{12} x_{2}+\ldots \ldots .+a_{p 1} x_{p}
$$




$$
\begin{gathered}
y_{2}=a_{12} x_{1}+a_{22} x_{2}+\ldots \ldots .+a_{p 2} x_{p} \\
\vdots \\
y_{p}=a_{1 p} x_{1}+a_{2 p} x_{2}+\ldots \ldots .+a_{p p} x_{p}
\end{gathered}
$$

Each component is a weighted sum of the $x$, $s$, where the $a_{i j}$ 's are the weights or coefficients, for variable $i$ and $j$. Where

$$
\sum_{i=1}^{p} a_{i j}^{2}=1 \quad(j=1,2, \ldots, p)
$$

and

$$
\sum_{i=1}^{p} a_{i j} a_{i k}=0 \quad(j \neq k ; j=1,2, . . p ; k=1,2, \ldots, p)
$$

Consequently, the total variance of the $y^{\prime} s$ is equal to the total variance of the $x$ 's, that is

$$
\sum_{j=1}^{p} \operatorname{var}\left(y_{j}\right)=\sum_{i=1}^{p} \operatorname{var}\left(x_{i}\right)
$$

This means that the total variance does not change; rather variance is redistributed in such a way that the most important component $y_{1}$ has maximum variance and, therefore, explains the largest proportion of the total variance.

When choosing the number of components, the aim is to retain as small set as possible but at the same time have a significant number that provide good representation of the original data.

The variance of component $j$ is the eigenvalue $\lambda_{j}$. Since the components are derived in order of variance, $\lambda_{1} \geq \lambda_{2} \geq \cdots \geq \lambda_{p}$. If the $x^{\prime} s$ are standardized so that the correlation matrix is analysed, the sum of the variances of the $x^{\prime} s$ will be equal to $p$. Thus the sum of the eigenvalues, the total variance of the $y^{\prime} s$, will be equal to $p$.

The proportion of total variance explained by component $j$ is

$$
\frac{\lambda_{j}}{\lambda_{1}+\lambda_{2}+\cdots+\lambda_{p}}
$$

The proportion explained by the first $\mathrm{k}$ component together is

$$
\frac{\lambda_{1}+\lambda_{2}+\cdots+\lambda_{k}}{\lambda_{1}+\lambda_{2}+\cdots+\lambda_{p}}
$$

Amongst the criterion used to decide the number of component to retain, the correlation matrix is most preferred. In this study, correlation matrix is analysed and component with eigenvalue greater than one is retained.

\section{Results and Discussions}

Principal component analysis with varimax rotation was conducted to assess the underlying structure of the sixty-five items for the socio-economic and environmental variables of mortality rates. The normality assumptions, as well as the linear relationships between pairs of variables, and the variables being correlated at a moderate level were checked. Eleven factors component was identified. The total variance explained is 90.38 . The result shows that 30.8 per cent of the variance was accounted for by the first factor while the second and third factors accounted for 16.5 per cent and 15.3 per cent respectively. It is particularly instructive to note that more than 60 percent of the variance is accounted for by the first three factors. Table 1 displays the variables and factor loadings for the rotated factors, with loadings less than .60 omitted to improve clarity.

The first factor which seems to index household dwelling infrastructure had a very strong loadings on infant immunization, type of cooking fuel, type of main roofing material, floor material, method of solid waste disposal and refuse disposal facility as well as household monthly income. The second factor which seemed to index maternal education had high loadings on households' sanitation facility, drinking water, access to electricity, maternal education and type of housing unit. "Type of housing" unit had its highest loading from the third factor which seemed to index income, but had a cross-loading factor over .7 on the maternal education factor. 
The fourth, fifth, and the seventh factor indexed unemployment/mud house, unhealthy household waste disposal and rich household respectively. Type of refuse disposal facility and method of solid waste disposal which had their highest loading factor in household environment factor also had a strong loading from the unhealthy waste disposal facility management factor.

\subsection{Multiple Regression}

Multiple regression was conducted to determine the best linear combination of the eleven identified factor components for predicting mortality rates. The result is presented in Table 2.

The table shows that the adjusted r-squared value was 0.43 , meaning that 43 per cent of the variance in mortality rate are explained by the model. The standardized beta coefficient and beta weights presented in Table 2 suggest that immunization/household dwelling infrastructure/low polluting fuel factor contribute most to predicting mortality rate and that income factor and unsafe water factor also contribute to this prediction. For robustness, a stepwise regression was conducted as model selection technique in order to ascertain the major determinant factors contributing to mortality rate prediction. The result is presented in Table 3.

The combination of the household environmental factor significantly predicted mortality rate, $F=13.12, p$ $<.004$ with the immunization/household dwelling infrastructure/low polluting fuel factor significantly contributing to the prediction. The adjusted r-squared value was 0.48 . This indicates that 48 per cent of the variance in mortality rate was explained by the model. According to Cohen (1988), this is a large effect. The beta weight presented in Table 2, suggest that immunization, low polluting fuel and household dwelling infrastructure such as method of solid waste disposal, refuse disposal facility, roofing and flooring material used, as well as income factor contribute most to predicting mortality rate.

\section{Conclusion and Policy Implications}

Child mortality has become the burning issue and a topic of interest to population research owing to its obvious direct link with lack of health facilities and indirect relationship with poverty. This study has empirically examined the environmental determinants of child mortality in Nigeria using principal component factor analysis and simultaneous multiple regression. For purpose of robustness, a model selection technique procedure was implemented. Estimation from the stepwise regression model has shown that household environmental characteristics do have significant impact on child mortality.

As for the socio-economic variables, better survival prospect are found to exist in homes with high income. Lower mortality rate have also been found in smaller household. As expected, environmental characteristics of the household has been found to be significantly related to child mortality. Lower mortality rates are experienced in household that have access to immunization, those with sanitation facilities, those with good and proper refuse and solid waste disposal facilities as well as those with good healthy roofing and flooring materials and those using low polluting fuels as their main source of cooking.

In view of the fact that Nigeria has committed to the Millennium Development Goals, the fourth of which is the reduction of child mortality, the country should continuously thrive to achieve these goals. Worthy of note will be the mainstreaming of the MDGs into the current national policy of economic transformation goal of the economic team. Greater effort should be put in place to ensure adequate provision of healthcare and basic services like good waste management facilities, access to good sanitation facilities as this will to a larger extent reduce the number of child mortality. Government policy should be tilted toward promoting the use of low polluting fuels and discourage in particular, the use of firewood and charcoal which causes deforestation and other environmental problems. This will reduce the rate of childhood mortality by over sixty percent.

Economic mechanisms that encourage cleaner fuel sources should be created, as this will generate employment opportunities that will translate into increased earnings and poverty reduction.

\section{References}

Adebayo, S. B. \& Fahrmeir, L. (2002). Analyzing Child Mortality in Nigeria with Geoadditive Survival Models. Sonderforschungsbereich 386, Paper 303. [Online] Available: http://epub.ub.uni-muenchen.de/ (August 26, 2011)

Adeyemi, S. L., Raheem, U. A. \& Olorunfemi, F. B. (2008). Under-Five Mortality and the Environment of Health in the Third World: A Nigerian Example. Journal of Human Ecology, 24 (2), 117-124.

Animashaun, A. (1977). Measles and blindness in Nigerian children. Nigeria Journal of Paediatrics, 4 (1), $10-13$. 
Antai, D. (2010). Migration and Child Immunization in Nigeria: Individual and Community-level Contexts. BMC Public Health, 10 (1). http://dx.doi.org/10.1186/1471-2458-10-116

Ayeni, O. \& Oduntan, S. O. (1980). Infant mortality rates and trends in Nigerian rural populations. Journal of Tropical Paediatrics and Environmental Child Health, 26 (1), 7-10.

Bartholomew, D. J., Steele, F., Moustaki, I. \& Galbraith, J. (2002). The Analysis and Interpretation of Multivariate Data for Social Scientists. Chapman \& Hall/CRC, Florida.

Baxter-Grillo, D. L. \& Leshi, F. E. A. (1964). Factors influencing the occurrence of Neonatal tetanus in Ibadan. West African Medical Journal, 13.

Caldwell, J. C. (1979). Education as a Factor in Mortality Decline: An Examination of Nigerian Data. Population Studies, 33 (3), 395-413. http://dx.doi.org/10.2307/2173888

Cohen, J. (1988). Statistical power and analysis for the behavioural sciences (2nd Ed.). Hillsdale, NJ: Lawrence Erlbaum Associates.

Cousins, M. S., Shickle, L. M. \& Bander, J. A. (2002). An Introduction to Predictive Modeling for Disease Management Risk Stratification. Disease Management, 5 (3), 157-67. http://dx.doi.org/10.1089/109350702760301448

Espo, M. (2002). Infant Mortality and its underlying Determinants in Rural Malawi (Dissertation). University of Tampere Medical School.

Ewbank, D. C. \& Gribble, J. N. (1993). Effects of Health Programmes on Child Mortality in Sub-Saharan African. Washington: National Academy Press.

Folasade, B. (2000). Environmental factors, situation of women and child mortality in South Western Nigeria. Social Science \& Medicine, 51, 1473-1489. http://dx.doi.org/10.1016/S0277-9536(00)00047-2

Gray, R. H., Campbell, O. M., Apelo, R., Eslami, S. S., Zacur, H. \& Ramos, R. M. (1990). Risk of ovulation during lactation. Lancet, 335, 25-29. http://dx.doi.org/10.1016/0140-6736(90)90147-W

Guyatt, H. L., Snow, R. W. \& Evans, D. B. (1999). Malaria Epidemiology and Economics: The Effect of Delayed Immune Acquisition on the Cost-effectiveness of Insecticide-treated Bednets. The Royal Society, 354, 827-835.

Hala, A. (2002). The effect of water and sanitation on child mortality in Egypt. Environmental Economics Unit, Department of Economics, Gothenburg University.

Jacoby, H. \& Wang, L. (2003). Environmental Determinants of Child Mortality in Rural China: A Competing Risks Approach. Washington DC: World Bank.

Jada, L. F. (1992). Determinants of levels and differentials of early childhood mortality in Kenya based on Kenya Demographic and Health Survey (KDHS) 1989 (MA Thesis). Population Studies and Research Institute, University of Nairobi.

Jinadu, M. K., Olusi, S. O., Agun, J. I. \& Fabiyi A. K. (1991). Childhood diarrhoea in rural Nigeria: Studies on prevalence, mortality and socio-environmental factors. Journal of Diarrhoea Diseases Research, 9 (4), 323-327.

Klaauw, van der B. \& Wang, L. (2003). Child Mortality in Rural India. World Bank Working Paper, Washington DC: World Bank.

Leech, N. L., Barrett, K. C. \& Morgan, G. A. (2008). SPSS for Intermediate Statistics: Use and interpretation ( $3^{\text {rd }}$ edition). Taylor \& Francis, New York.

Mesike, G. C., Adeleke, I. A. \& Ibiwoye, A. (2012). Predictive Actuarial Modeling of Health Insurance Claims Costs. International Journal of Mathematics and Computation, 14 (1).

Mojekwu, J. N. \& Ajijola, L. A. (2011). Developing a Model for Estimating Infant Mortality rate of Nigeria. Journal of Research in International Business and Management, 1 (2), 164-170.

Mosley, W. \& Chen, L. (1984). An Analytical Framework for the Study of Child Survival in Developing Countries, Population and Development Review, 10, 25-45. http://dx.doi.org/10.2307/2807954

Morley, D. (1973). Paediatric Priorities in the developing world, London: Butterworths.

Mutunga, C. J. (2007). Environmental Determinants of Child Mortality in Kenya. UNU-WIDER Research paper No. 2007/83. Helsinki: United Nations University World Institute for Development Economics Research.

NDHS. (2008). Nigeria Demographic and Health Survey. 
NBS. (2009). Annual Abstracts of Statistics, 2009. National Bureau of Statistics.

Ogunlesi, T. O. (1961). Respiratory infections in the preschool child: A review of 435 cases admitted to Adeoyo Hospital, Ibadan. West African Journal, 10, 231.

Ogunjuyigbe, P. O. (2004). Under-Five Mortality in Nigeria: Perception and Attitude of the Yoruba towards the Existence of Abiku. Demographic Research, 11 (2).

Ojikutu, R. K. (2008). Pattern of Under-Five Deaths in Lagos State, Nigeria. Sudanese Journal of Public Health, 3 (4).

Ojikutu, R. K. (2010). Malaria and Child Survival in Nigeria: Beyond the Stethoscope. International Journal of Academic Research, 2 (2).

Okumbe, J. (1996). Demographic and socio-economic correlates of Neonatal mortality in Kenya (MA Thesis). Population Studies and Research Institute, University of Nairobi.

Omariba, D. W. R. (1993). Socio-economic determinants of child survival in Upper Matasia sub-location, Kajiado district, Kenya (MA Thesis). Population Studies and Research Institute, University of Nairobi, Kenya.

Ouma, F. O. (1991). Environmental risk and socio-economic factors influencing infant and child mortality in Siaya district: A case study of Jera sub-location (MA Thesis). Population Studies and Research Institute, University of Nairobi.

Ozumba, B. C. \& Nwogu-Ikojo, E. E. (2008). Avoidable Maternal in Enugu, Nigeria. Public Health, 122 (4), 354-360. http://dx.doi.org/10.1016/j.puhe.2007.04.018

Rahman, K. M. M. \& Sarkar, P. (2009). Determinants of Infant and Child Mortality in Bangladesh. Pakistan Journal of Social Sciences, 6 (3), 175-180.

Ridder, G. \& Tunali, I. (1991). Stratified partial likelihood estimation. Journal of Econometrics, 92, 193-232. http://dx.doi.org/10.1016/S0304-4076(98)00090-6

Schultz, T. (1984). Studying the Impact of Household Economic and Community Variables on Child Mortality. Population and Development Review, 10, 215-35. http://dx.doi.org/10.2307/2807962

Shyamsundar, P. (2002). Poverty-Environment Indicators. World Bank Environmental Department Paper, Washington, DC: World Bank.

Smith, E. G. (2010). Maternal Schooling and Child Mortality in Nigeria: The importance of the actual curriculum. [Online] Available: Princeton.edu/download.aspx? submissionld=100377 (February 18, 2011)

Timeaus, I. M. \& Lush, L. (1995). Intra-urban differentials in child health. Health Transition Review, 5 (2), 163-90, Canberra: Health Transition Centre.

UNICEF. (1999). The State of the World's Children 1999, New York: UNICEF.

UNICEF. (2010). Levels and Trends in Child Mortality, Report 2010, New York: UNICEF.

Wang, L. (2003). Environmental Determinants of Child Mortality: Empirical Results from the 2000 Ethiopia DHS. Washington DC: World Bank.

Wanjohi, K. P. (1996). The influence of environmental factors on infant and child mortality: A study of six districts in Kenya (MA Thesis). Population Studies and Research Institute, University of Nairobi.

World Bank. (2001). Health and Environment. Background paper for the World Bank Environment Strategy, Washington, DC: World Bank.

World Bank. (2004). World Development Indicators (WDI). The World Bank Online Database, Washington, DC: World Bank.

World Health Organisation. (2002). The world health report 2002: Reducing risks, promoting healthy life, Geneva: World Health Organisation.

WRI (World Resources Institute). (1999). World Resources (1998-99): Environmental change and Human Health, Washington DC: World Bank.

Zhao, Y., Ash, S. A., John H. \& Benjamin, M. (2003). Identifying Future High-Cost Cases through Predictive Modeling. Disease Management and Health Outcomes, 11 (6), 389-97. http://dx.doi.org/10.2165/00115677-200311060-00005 
Table 1. Factor loadings for the rotated factors

\begin{tabular}{|c|c|c|c|c|c|c|c|c|c|c|c|}
\hline \multirow[b]{2}{*}{ Items } & \multicolumn{11}{|c|}{ Factor Loading } \\
\hline & 1 & 2 & 3 & 4 & 5 & 6 & 7 & 8 & 9 & 10 & 11 \\
\hline \multicolumn{12}{|l|}{$\begin{array}{c}\text { Household sanitation } \\
\text { facilities }\end{array}$} \\
\hline Has sanitation & & 0.62 & & & & & & & & & \\
\hline No Sanitation & & 0.62 & & & & & & & & & \\
\hline \multicolumn{12}{|l|}{ Household drinking water } \\
\hline Safe water & & 0.78 & & & & & & & & & \\
\hline Unsafe water & & & & & & & & & & & 0.78 \\
\hline \multicolumn{12}{|l|}{$\begin{array}{c}\text { Household access to } \\
\text { electricity }\end{array}$} \\
\hline Electricity & & 0.78 & & & & & & & & & \\
\hline No electricity & & 0.77 & & & & & & & & & \\
\hline \multicolumn{12}{|l|}{ Maternal Education } \\
\hline Mother with education & & 0.84 & & & & & & & & & \\
\hline Mother without education & & 0.84 & & & & & & & & & \\
\hline \multicolumn{12}{|l|}{ Employment status } \\
\hline Employed & & & & 0.95 & & & & & & & \\
\hline Not employed & & & & 0.95 & & & & & & & \\
\hline \multicolumn{12}{|l|}{ Poverty headcount } \\
\hline Rich & & & & & & & 0.87 & & & & \\
\hline Poor & & & & & & & 0.87 & & & & \\
\hline $\begin{array}{c}\text { Average person per } \\
\text { household }\end{array}$ & & & & 0.71 & & & & & & & \\
\hline \multicolumn{12}{|l|}{$\begin{array}{c}\text { Infant immunization } \\
\text { (antigen) }\end{array}$} \\
\hline OPV3 & 0.85 & & & & & & & & & & \\
\hline DPT3 & 0.91 & & & & & & & & & & \\
\hline MV & 0.8 & & & & & & & & & & \\
\hline \multicolumn{12}{|l|}{ Type of cooking fuel } \\
\hline Low polluting fuel & 0.73 & & & & & & & & & & \\
\hline High polluting fuel & -0.73 & & & & & & & & & & \\
\hline \multicolumn{12}{|l|}{$\begin{array}{c}\text { Type of main roofing } \\
\text { material }\end{array}$} \\
\hline $\begin{array}{l}\text { Thatcch/Palm } \\
\text { Leaves/Raffia }\end{array}$ & & 0.81 & & & & & & & & & \\
\hline Wood/bamboo & & 0.71 & & & & & & & & & \\
\hline Earth/Mud/Mud Bricks & & & & 0.72 & & & & & & & \\
\hline \multicolumn{12}{|l|}{ Corrugated Metal/Zinc } \\
\hline \multicolumn{12}{|l|}{ Sheet } \\
\hline Slate/ Asbestos & 0.94 & & & & & & & & & & \\
\hline Cement/Concrete & 0.96 & & & & & & & & & & \\
\hline Roofing Tiles & 0.95 & & & & & & & & & & \\
\hline \multicolumn{12}{|l|}{ Type of floor } \\
\hline Earth/Mud/Mud Bricks & & 0.8 & & & & & & & & & \\
\hline Wood/Bamboo & & 0.73 & & & & & & & & & \\
\hline Cement/ Concrete & 0.94 & & & & & & & & & & \\
\hline \multicolumn{12}{|l|}{ Stone } \\
\hline Burnt Brick & & & & & & & & & & & \\
\hline
\end{tabular}


Table 1. Factor loadings for the rotated factors (continued)

\begin{tabular}{|c|c|c|c|c|c|c|c|c|c|c|c|}
\hline Vinyl Tiles & 0.92 & & & & & & & & & & \\
\hline Ceramic/Mable Tiles & 0.89 & & & & & & & & & & \\
\hline Terrazzo & 0.95 & & & & & & & & & & \\
\hline Other & 0.83 & & & & & & & & & & \\
\hline \multicolumn{12}{|l|}{$\begin{array}{l}\text { Method of solid } \\
\text { waste disposal }\end{array}$} \\
\hline Collected & 0.97 & & & & & & & & & & \\
\hline Buried by Household & & & & & 0.74 & & & & & & \\
\hline $\begin{array}{l}\text { Public Approved } \\
\text { Dump Site }\end{array}$ & 0.92 & & & & & & & & & & \\
\hline $\begin{array}{l}\text { Unapproved Dump } \\
\text { site }\end{array}$ & & & & & & & \multicolumn{5}{|c|}{0.61} \\
\hline \multicolumn{12}{|l|}{ Burnt by Household } \\
\hline Other & & & & & & & & 0.88 & & & \\
\hline \multicolumn{12}{|l|}{$\begin{array}{l}\text { Type of refuse } \\
\text { disposal facility }\end{array}$} \\
\hline $\begin{array}{l}\text { HH Bin collected by } \\
\text { Government }\end{array}$ & 0.94 & & & & & & & & & & \\
\hline $\begin{array}{l}\text { HH Bin collected by } \\
\text { private agency }\end{array}$ & 0.88 & & & & & & & & & & \\
\hline $\begin{array}{l}\text { Government bin or } \\
\text { shed }\end{array}$ & & & & & & 0.92 & & & & & \\
\hline $\begin{array}{l}\text { Disposal within } \\
\text { compound }\end{array}$ & & & & & 0.74 & & & & & & \\
\hline $\begin{array}{l}\text { Unauthorized refuse } \\
\text { heap }\end{array}$ & & & & & -0.7 & & & & & & \\
\hline Other & & -0.79 & & & & & & & & & \\
\hline \multicolumn{12}{|l|}{ Type of housing unit } \\
\hline Single room & & 0.8 & & & & & & & & & \\
\hline Flat & & & 0.84 & & & & & & & & \\
\hline Duplex & & & 0.76 & & & & & & & & \\
\hline Whole Building & & 0.78 & & & & & & & & & \\
\hline Other Types & & & & & & & & & & & 0.78 \\
\hline \multicolumn{12}{|l|}{$\begin{array}{l}\text { Household monthly } \\
\text { income }\end{array}$} \\
\hline 1 to 20 & & & 0.89 & & & & & & & & \\
\hline $21-40$ & & & 0.82 & & & & & & & & \\
\hline $41-60$ & & & 0.9 & & & & & & & & \\
\hline $61-80$ & & & 0.94 & & & & & & & & \\
\hline $81-100$ & & & 0.79 & & & & & & & & \\
\hline $101-120$ & 0.81 & & & & & & & & & & \\
\hline $121-140$ & 0.74 & & 0.64 & & & & & & & & \\
\hline $141-160$ & & & 0.75 & & & & & & & & \\
\hline $161-180$ & & & 0.88 & & & & & & & & \\
\hline $181-200$ & & & & & & & & & & 0.86 & \\
\hline $201-400$ & 0.87 & & & & & & & & & & \\
\hline $401-600$ & 0.9 & & & & & & & & & & \\
\hline $601-800$ & & & & & & & & & 0.87 & & \\
\hline Above 800 & & & & 0.68 & & & & & & & \\
\hline Eigenvalues & 20.01 & 10.7 & 9.92 & 5.18 & 3.71 & 2.81 & 2.76 & 2.52 & 2.18 & 2.17 & 1.98 \\
\hline$\%$ of variance & 30.78 & 16.46 & 15.26 & 7.97 & 5.71 & 4.33 & 4.25 & 3.87 & 3.36 & 3.34 & 3.05 \\
\hline
\end{tabular}


Table 2. Multiple regression of the rotated component factors on mortality

\begin{tabular}{|c|c|c|c|c|}
\hline Variables & $\mathrm{B}$ & SEB & Beta & p-value \\
\hline $\begin{array}{l}\text { Immunization/ Household } \\
\text { dwelling infrastructure/ Low } \\
\text { polluting fuel }\end{array}$ & 51.70002992 & 14.98221045 & 0.722694 & 0.074692 \\
\hline Maternal education & -11.4310058 & 14.98221045 & -0.15979 & 0.52519 \\
\hline Household Income & 18.01067198 & 14.98221045 & 0.251764 & 0.352334 \\
\hline Unemployment/mud house & -3.20902278 & 14.98221045 & -0.04486 & 0.850253 \\
\hline $\begin{array}{l}\text { Unhealthy refuse disposal } \\
\text { practice }\end{array}$ & -15.1879875 & 14.98221045 & -0.21231 & 0.417399 \\
\hline Refuse disposal & 1.359985967 & 14.98221045 & 0.019011 & 0.935945 \\
\hline Rich household & -1.16264995 & 14.98221045 & -0.01625 & 0.94521 \\
\hline Other factors & -18.8395435 & 14.98221045 & -0.26335 & 0.335523 \\
\hline Proximity to dump site & -7.6666729 & 14.98221045 & -0.10717 & 0.65975 \\
\hline Household Income & -16.0549676 & 14.98221045 & -0.22443 & 0.396061 \\
\hline Unsafe water & 25.00298805 & 14.98221045 & 0.349507 & 0.23709 \\
\hline (Constant) & 106.1428571 & 14.43721923 & & 0.018003 \\
\hline
\end{tabular}

$\mathrm{R}^{2}=.91 ; \overline{\operatorname{Adj} \mathrm{R}^{2}=.43}$

Table 3. Stepwise multiple regression for the factor score

\begin{tabular}{ccccc}
\hline Variable & B & SEB & P-value \\
\hline $\begin{array}{c}\text { Immunization/ Household } \\
\text { dwelling infrastructure/ Low } \\
\text { polluting fuel }\end{array}$ & 51.700 & 14.273 & 0.723 & 0.004 \\
Constant & 106.143 & 13.754 & & 0.000 \\
\hline
\end{tabular}

$\mathrm{R}^{2}=.52 ; \mathrm{F}=13.12 ; \operatorname{Adj} \mathrm{R}^{2}=.48$ 